\title{
Leveraging robo-advisors to fill the gap within the SRI marketplace
}

\author{
Dimitrios Salampasis \\ Lecturer of Entrepreneurship and Innovation, Swinburne Business School, Faculty of Business \\ and Law, Swinburne University of Technology, Australia \\ dsalampasis@swin.edu.au \\ Letter from Academia
}

\begin{abstract}
The Socially Responsible Investing (SRI) marketplace has been experiencing continuous growth, despite the limited understanding and comprehensive tools for assessment, reporting, measurement and profiling of the investment portfolios, the risk and the generated impact. The materialization of roboadvisors, a new offering within the fund management industry, in the light of continuous technological developments, brings a new wave of innovation that aims at assisting the industry towards institutionalizing SRI strategies for the purpose of social good.
\end{abstract}

Keywords. SRI, Investment Strategies, Robo-Advisors, Artificial Intelligence, Fund Managers, Impact, ESG.

\section{Introduction}

In 1987, a TV series called Star Trek and the new generation of Starfleet officers on board the starship Enterprise, having the mission of travelling where no one had gone before, brought a different perspective in TV science fiction shows and space exploration. Among the crew of the Enterprise was Lt. Commander Data, an artificial life form officer, who looked exactly like a human being, always trying to imitate and sometimes endeavoring to capture the feelings and mysteries of the human nature. However, Data was a machine, who was able to conduct series of multiple and high complex algorithmic calculations, while providing advice to the rest of the crew on critical matters, based on rational calculations, historical data and formulas. 30 years have passed since the broadcast of the 1" episode of Star Trek and the introduction to our lives of the concept of an artificial life form. At that time this was still considered an element within the sphere of science fiction, however, 30 years later, robo-advisors are gradually becoming a real part of our lives, in different forms and contexts...

The aim of this brief letter, anchored in the ongoing disruptive developments across the FinTech landscape, is to provide some insights, on the emerging role of robo-advisors within the Sustainable, Responsible and Impact Investing (hereinafter SRI) terrain and interrelated opportunities challenges this entails for the fund/wealth management industry. 


\section{Sustainable, Responsible and Impact Investing Strategies}

SRI stills remains an elusive and multidimensional notion capturing many interconnected, interrelated and difficult to understand elements that exist individually, but neither necessarily interdependently nor constantly. This multidimensionality has been extensively explored but there is still no broad consensus around a conceptual framework that captures the various and different dimensions of Sustainable, Responsible and Impact Investing.

The core of SRI is grounded into the co-existence of investors' financial objectives and their concerns about Environmental, Social and Governance (ESG) issues within an investment process. SRI is branched into responsible, sustainable and impact investing. Each of these three pillars incorporates a number of investment strategies, which can be complementary and can be deployed in various (and often blended ways) ways by the investor in the process of incorporating ESG criteria.

The broader area of responsible investing has been experiencing an increased growth, along with, raising of awareness, within the past decade. US-domiciled AuM adopting SRI strategies increased to $\$ 8.72$ trillion within 2016, an increase of 33\% since 2014 (USSIF, 2016). Moreover, global sustainable investment assets reached approx. \$22.9 trillion AuM, experiencing a 25.2\% increase since 2014 (GSIA, 2016). Furthermore, within the European landscape, SRI strategies remained within a growing trajectory, 'with rates between $14 \%$ and $57 \%$ CAGR for the main strategies, while Impact Investing-still the fastest growing strategy-is at 120\% CAGR' (Eurosif, 2016, p.12). These numbers show indeed a marketplace with great potential and demand, also in the light of the recent developments in the Sustainable Development Goals (SDG) landscape and the continuous willingness from different cohorts of investors to align their investment objectives with their values and the generation of positive social and/or environmental impact. However, this has not always been the case since primarily, in this context, investing has been associated the notion of responsibility (exclusionary process) substantially diminishing the investable area and leading to a potential negative investment performance, by either increasing risk and/or reducing returns. In addition, responsible investing and the societal element that it entails has been for long considered as a taboo, since it was contradictory to the prevailing narrative that the asset manager's fiduciary duty is all about financial return maximization.

Within the last couple of years, the incorporation of ESG criteria (which in many cases was conducted in a non-systematic and unstructured way) has moved beyond the traditional negative screening process (which is primarily based on ethical and/or normbased considerations) to a more active and positive approach i.e. focusing on companies that depict a positive score on ESG factors, but also show tangible progress in the way they score on ESG factors.

One of the foundational and most important elements within the responsible investing landscape is the practical integration of ESG considerations into the process of investment decision-making (pre-investment diligence but also post-investment monitoring) [USSIF, 2015]. In simple terms, ESG integration goes beyond the analysis and assessment of corporate financial data. It provides additional valuable content by including into the analysis intangible factors related to environmental, social and governance issues. ESG integration is defined as "the explicit inclusion by asset 
managers of ESG risks and opportunities into traditional financial analysis and investment decisions based on a systematic process and appropriate research sources" (Eurosif, 2014, p.17)). ESG integration brings on board a proactive approach in terms of managing the investment process across various asset classes, traditional financial performance metrics and practices of managing risk (Zurich Insurance, 2014). It is important to clarify that even though positive and negative screening tactics are by default embedded within ESG factors, ESG integration brings an alternative way of looking into the ESG analysis that goes beyond the standalone screening approaches (NEPC, 2015).

Looking beyond the monolithic way of acting responsibly, the integration of ESG criteria within the investment decision-making process brings a consolidated approach in the investment strategy since it emanates sustainability; the overall aim of this kind of investment strategy is about investing in sustainable and innovative business models that in the long-run can lead to positive investment performance. In this context, a number of studies has shown that the incorporation of ESG factors within the assessment of the investing portfolio can have a positive impact on the investment performance and failure or ommitance to include can lead to incomplete or even incorrect investment decision-making (Eccles, and Serafeim, 2013; Isaksson, and Woodside, 2016; van Duuren et al., 2016).

\section{Positive impact on global challenges}

Governments have, for long, been considered as a monopoly when it comes to dealing with social and/or environmental issues; however, their role in terms of providing answers to diversified societal needs has been disappointing in the eyes of people interested in social issues. In this frame of reference, the impact investing paradigm, which gradually gains momentum in the marketplace, channels innovation, entrepreneurship and capital to empower social progress, allowing for an alternative mindset towards investments.

Impact investing, as an investment management strategy across asset classes, brings an entire different logic within the responsible investing landscape, which, at the same time, creates a number of crucial challenges requiring immediate attention. In fact, the primary challenge originates from the very multidisciplinary nature of impact investing.

What makes impact investing unique is the dynamic co-existence of generation and demonstration of intentional (and unintentional) impact, both in a clear and attributable manner. By definition impact investing is the active placement of intentional capital (incl. non-monetary activities) to enterprises with the purpose of generating social and/or environmental impact (ultimate social outcome), along with, expectations of financial return and consideration of risk. According to these existing narratives and definitional considerations, impact investing is projected in a three-dimensional spectrum: impact, risk and return, with each of these pillars h0lding a fundamental role in the impact investing landscape.

One of the foggiest and highly debatable aspects of impact investing is related to the understanding, the measurement and the reporting of the perceived and generated 
impact and calculation of social good. Measurement of social impact is considered as a paramount enabler in the process of achieving financial and social returns, since it really identifies and scales what actually makes sense and works in alignment with social objectives (intentional and unintentional). It is a tool that enables access to capital and opens door to innovation by allowing investors perceive a social and philanthropic pathway.

However, the high-quality measurement of social impact, along with, the reporting mechanisms are considered as the dark side of impact investing. This fact is primarily grounded on the limited development and adoption of concrete impact indicators, tools and processes for assessing development (social) impact and financial performance. Needless to say, that, this measurement and reporting deficit, along with, often observed lack of transparency, additionallity, honesty and accountability, hinder the credibility of impact investing, especially, in the eyes of tax-payers who are expecting the generation of tangible social impact. Furthermore, it creates strong ambiguity in the eyes of investors. In this frame of reference, this discussion is cutting-edge since it is all about connecting the measurement of social impact with capital markets in order to create a powerful force to improve the lives of others within underserved markets.

A number of industry-sponsored organizations have put together sophisticated and often "competing" measurement frameworks, indicators, reporting metrics and platforms (e.g. IRIS, PULSE and GIIRS). Still, a common language around impact measurement is missing and not a widely accepted definition of social value exists so far. This reality is also reflected in the inherent difficulty to integrate concise reporting procedures. Consumers, investors and donors are constantly inquiring for a magnitude of information. This becomes crucial for organizations to be able to provide such kind of information in a meticulous, rigorous and trustworthy manner, contributing to their reputation and leadership within their respective markets.

This nascent investment area is still in its infancy and endeavors towards developing more standardized approaches, which are of relevance for different sectors, move at a glacial pace. Furthermore, time and cost are considered as key barriers when it comes to integrating impact measurement methods and tools in the investment and decisionmaking process, both in the pre-investment due diligence, the pre-approval and the post-investment monitoring phases.

So and Staskevicius (2015) propose five key measurement objectives, which can be integrated into the investment cycle:

- Estimating impact: this objective corresponds to the pre-investment due diligence phase. During this phase impact investing organizations determine the impact that the potential investment may create, allowing the investors to prioritize the allocation of resources in such a way that can create the intended impact;

- Planning impact: this objective corresponds to the pre-approval phase. During this phase impact investing organizations enter into a negation and/or shortlypost investment cycle, developing all the necessary tools and methodologies to plan the impact measurement; 
- Monitoring impact: this objective is part of the post-investment monitoring phase. In this part of the phase progress is monitored by the reporting of data, information, financial elements etc. This objective may also serve the purpose of re-organizing and re-visiting part of the project and investment portfolio in order to apply "corrective interventions";

- Evaluating impact: The use of the word "evaluation" hereby allows for the unveiling of insights in relation to context, strategy, organizational, human and system capabilities, elements that cannot be measured with traditional means. Evaluation brings together a broader perspective into the understanding of impact moving beyond the measurement narrative;

- Reporting impact: This objective is all about external communication of the project/investment outcomes to the beneficiaries.

Brest and Born (2013), introduce three basic parameters of impact:

- Enterprise impact: "the social value of the goods, services, or other benefits provided by the investee enterprise"

- Investment impact: "a particular investor's financial contribution to the social value created by an enterprise" and

- Non-monetary impact: "reflects the various contributions, besides dollars, that investors, fund managers, and others may make to the enterprise's social value"

The biggest question when it comes to impact investing measurement is to determine if the investment actually has an impact. It is also important to understand and decide on what can and cannot be measured, because even though many things have a social return it does not mean they can generate a financial return. Funds that some may consider to be inherently impactful based solely on the investment portfolio cannot be considered as impact investing. The key determinant is the intent of the fund manager. Being an investor in an impact theme sector does not automatically grant an impact investor status; fund managers must be able to demonstrate their intentionality in terms of creating positive impacts as part of their core strategy. Moreover, funds, which only seek to encourage an ESG-minded philosophy within their portfolio companies cannot be put in the impact investing landscape. Naturally, these kind of policies may certainly generate societal benefits, but this is not an adequate indicator for social impact generation.

The measurement of social impact needs also to take into consideration the factor of time and the element of counterfactual. However, social problems are intractable and they cannot be solved overnight. But, this does not mean that positive outcomes are not created. To that respect, fund managers need to look for correlation rather than direct causality in their process of understanding and developing the investment strategies. They also need to see the collective impact generated via the collaboration of different impact investors both on tackling community-based projects and on the sector, which can have create a paradigm shift, beyond the particular mission.

Despite the growth and integration of ESG factors there are still a number of challenges and gaps, which need to be addressed: a) the application and disclosure of ESG criteria and the systematic and consistent ESG integration across asset classes. The existence of specialized ESG advisors possessing strong technical skills but also the ability to 
embrace alternative investment approaches and understand intangible and nonfinancial parameters, the clarification and standardization on labelling and the institutionalization of education and training programmes in order to build awareness and skills will help the responsible investment landscape become a truly mainstream market.

\section{Robo-advisors making SRI in demand}

The emergence of technological breakthroughs leading to new applications of Artificial Intelligence and Machine Learning, could not have left the SRI marketplace unattended. A number of 'socially conscious' robo or digital (automated) investment advisor platforms incl. Betterment, Wealthfront, Motif, Earthfolio, OpenInvest, M1 Finance, Passed Pawn Advisors, Hedgeable, Prophecy, Stash, TIAA Personal Portfolio, Wealthsimple, Swell and Grow Invest have emerged within a competitive SRI marketplace providing different values-based investing tools and investment portfolios built around SRI investing strategies, allowing socially conscious investors to tailor their own investment portfolio mix around socially conscious funds, assets or companies based upon their risk tolerance, investment objectives, values and in alignment with ESG criteria (incl. positive ESG performance indicators) and generation of a positive impact on the world. These online investment platforms either use algorithmic calculations or 'rules-based' investment approaches.

The increasing demand from investors (incl. millennials, Gen X, Baby Boomers) for blended investment portfolios that amplify their personal values while having the ability to generate positive financial returns, along with, the complexities of these investment portfolios and the limited institutional investing expertise, have provided room to automated investment advisor platforms to gain a considerable part of the SRI marketplace. Investing in innovative solutions to address numerous global challenges and the aspiration of accelerating long-lasting, sustainable social and/or environmental impact, within public and private markets, is one of the main reasons why investors are keen on exploring digital investment advisor platforms. In this context, the unique value proposition of such kind of platforms is related to the opportunity they provide to different cohorts of investors to experiment with different investing vehicles and tools emanating the symbiotic relationship between the market and society logic.

Based on the abovementioned analysis, the SRI landscape is characterized by a diverse 'multilingualism', which creates more confusion than understanding of the different and diverse tools that are available in the market; needless to say that primarily these human advisory options come with a substantial cost for the investor. The urge to incorporate ESG principles, along with, the ultimate willingness to craft investment portfolios that reflect personal norms and values tends to be the unique value proposition of these emerging automated platforms. However, the fundamental question remains: how is it possible for a robo-advisor to be able match personal and ethical values with investment portfolios? In other words, how can an automated investment advisor be able to capture the essence of responsibility, sustainability and impact based on algorithmic calculations and historical data, particularly when the current marketplace is so fragmented in terms of a comprehensive understanding of what the SRI landscape should look like? 


\section{Concluding remarks}

The fund management industry is definitely affected by all the applications emerging from various technological breakthroughs. Innovation is required both from a process point of view and an outcome point of view; innovation that would allow the generation of investing tools and vehicles that aim at providing pathways and funding mechanisms to novel business models that tackle pressing global challenges and wicked problems. The mental framework and state of mind of a new cohort of socially-conscious investors that is currently coming on the scene requires alternative functional, advisory and executional capabilities on behalf of investment advisors, along with, the ability to synthesize multiple parameters, factors and insights (financially and non-financially driven) that can lead to optimal outcomes. The evolution of 'hybrid' forms of advisory (combinative forces of human and AI capabilities) is expected to pave the way towards a comprehensive reconceptualization (learning, unlearning and relearning) of the SRI marketplace and democratize these types of investments for a good cause.

\section{$5 \quad$ References}

Brest, P., \& Born, K. (2013). When can impact investing create real impact? Stanford Social Innovation Review. Accessed 15th November 2017. http://ssir.org/articles/entry/unpacking_the_impact_in_impact_investing

Eccles, R.G. and Serafeim, G. (2013). The performance frontier. Harvard Business Review, 91(5), pp.50-60.

Eurosif (2016). 'European SRI Study 2016'. Accessed 15th November 2017. http://www .eurosif.org/wp-content/uploads/2017/11/SRI-study-2016-LR-.pdf

Eurosif (2014). 'European SRI Study 2014'. Available online at http://www .eurosif.org/wp-content/uploads/2014/09/Eurosif-SRI-Study20142.pdf

GSIA (2016). 'Global Sustainable Investment Review 2016'. Accessed 15th November 2017. http://www.gsi-alliance.org/wpcontent/uploads/2017/03/GSIR_Review2016.F.pdf

Isaksson, L.E. and Woodside, A.G. 2016. Capturing complexity in how configurations of firm Internal Orientations impact corporate social performance outcomes: Breaking from the dominant logic of symmetric-variable to asymmetric-casebased theory and testing. Australasian Marketing Journal, 24(4), pp.300-308

NEPC (2015). 'Completing the Analysis: ESG Integration'. Accessed 15th November 2017.

https://cdn2.hubspot.net/hubfs/2529352/Blog/2015_11_nepc_completing_the_a nalysis-_esg_integration.pdf?t=1486746354842

So, I., \& Staskevicius, A. (2015). Measuring the impact of impact investing. Harvard Business School. Accessed 15th November 2017. http://www.hbs.edu/socialenterprise/Documents/MeasuringImpact.pdf

USSIF (2016). 'Report on US Sustainable, Responsible and Impact Investing Trends'. Accessed 15th November 2017. http://www.ussif.org/trends 
USSIF (2015). 'Unblocking ESG Integration'. Accessed 15th November 2017.

http://www.ussif.org/files/Publications/UnlockingESGIntegration.pdf

van Duuren, E., Plantinga, A. and Scholtens, B. (2016). ESG integration and the investment management process: fundamental investing reinvented. Journal of Business Ethics, 138(3), pp.525-533

Zurich Insurance (2014). 'Responsible Investment in Zurich' 